\title{
Penatalaksanaan Fisioterapi untuk Meningkatkan Keseimbangan Dinamis Lansia dengan Teknik Core Stability Exercise dan Tandem Walking Exercise
}

\author{
${ }^{1}$ Enny Fauziah, ${ }^{2}$ Khairina Zulfah, ${ }^{3}$ Yulisha Eva Oktaviani \\ Program Studi DIII Fisioterapi, Politeknik Unggulan Kalimantan \\ Jln. Pangeran Hidayatullah, Komplek Upik Futsal No.10. Kec. Banjarmasin Utara, Kota Banjarmasin, \\ Kalimantan Selatan 70122. \\ Email : fauziahenny@gmail.com \\ Tanggal Submisi : 4 Mei 2021 ; Tanggal Penerimaan: 3 Desember 2021
}

\begin{abstract}
ABSTRAK
Lansia merupakan usia yang rentan akan mengalami jatuh. Hal tersebut disebabkan karena terjadinya penurunan kekuatan otot, rentang gerak sendi, sistem vestibular dan sistem visual. Semua permasalahan tersebut akan menyebabkan terjadinya gangguan keseimbangan dinamis pada lansia. Maka dari itu, pasien yang memiliki permasalahan keseimbangan dinamis harus diberikan intervensi yang tepat, salah satunya dengan menggunakan intervensi core stability exercise dan tandem walking exercise. Core stability exercise merupakan intervensi yang berfungsi untuk meningkatkan kekuatan core muscle. Sedangkan tandem walking exercise merupakan intervensi yang diberikan untuk meningkatkan aktivasi input proprioseptif. Tujuan penelitian ini adalah untuk mengetahui bagaimana penatalaksanaan fisioterapi pada gangguan keseimbangan dinamis lansia dengan pemberian intervensi berupa core stability exercise dan tandem walking exercise. Metode yang digunakan dalam penelitian ini menggunakan case study yaitu dengan melakukan pemeriksaan dan penanganan fisioterapi pada satu orang pasien. Penelitian ini dilakukan di Desa Paring Agung, Kecamatan Sungai Raya, Kabupaten Hulu Sungai Selatan. Penelitian ini dilakukan pada lansia yang memiliki masalah gangguan keseimbangan yang diukur dengan menggunakan timed up and go test. Dari hasil penelitian didapatkan bahwa pemberian intervensi core stability exercise dan tandem walking exercise dalam waktu 6 minggu dapat meningkatkan keseimbangan dinamis pada lansia.
\end{abstract}

Kata kunci: Lansia, keseimbangan dinamis, core stability exercise, tandem walking exercise

\begin{abstract}
The elderly are vulnerable to fall. This is due to decreased of muscle strength, range of joint motion, vestibular system and visual system. All of these problems will cause a dynamic balance disorder in the elderly. Therefore, patients who have dynamic balance problems must be given appropriate interventions, namely by using the intervention of core stability exercise and tandem walking exercise. Core stability exercise is an intervention that aims to increase the strength of core muscle. Whereas tandem walking exercise aims to increase proprioceptive input activation. The purpose of this study was to determine how the management of physiotherapy in the dynamic balance disorder of the elderly by providing interventon in the form of core stability exercise and tandem walking exercise The method used in this study is case study that is by examination and handling physiotherapy in one patient. This research was conducted on village Paring Agung, sub-district Sungai Raya, district Hulu Sungai Selatan. The study was conducted on the elderly who have problems with balance disorders as measured by using the timed up and go test. From the results of the study, it was found that the provision of core stability exercise and tandem walking exercisewithin 6 weeks could improve dynamic balance in the elderly.
\end{abstract}

Keywords: Elderly, dynamic balance, core stability exercise, tandem walking exercise 


\section{Pendahuluan}

Menjadi lansia merupakan suatu puncak dalam siklus kehidupan. Saat ini, dengan semakin ditingkatkannya perbaikan kualitas hidup masyarakat, maka akan berdampak pada peningkatan populasi lansia. Ketika individu memasuki masa tua, maka akan semakin banyak timbul permasalahan dikehidupannya, misalnya perubahan fisik, mental dan sosial sehingga akan mengakibatkan lansia tersebut mengalami ketergantungan dengan orang lain. Semakin meningkatnya usia maka akan memberikan dampak terhadap kondisi tubuh, seperti penurunan kekuatan otot, pengurangan rentang gerak sendi, dan penurunan fungsi organ vestibular dan visual sehingga dapat menyebabkan penurunan keseimbangan, yang merupakan faktor resiko jatuh tertinggi pada lansia (Shi \& Zhou, 2014).

Prevalensi populasi global yang berusia 60 tahun atau lebih berdasarkan data dari United Nation tahun 2017, terdapat 962 juta lansia pada tahun 2017 menjadi dua kali lebih besar daripada tahun 1980 ketika ada 382 juta lansia di seluruh dunia. Berdasarkan data Badan Pusat Statistik Lansia Indonesia (2018), persentase penduduk lansia Indonesia meningkat sekitar dua kali lipat. Pada tahun 2018, persentase lansia mencapai 9,27 $\%$ atau sekitar 24,49 juta orang. Di Provinsi Kalimantan Selatan memiliki jumlah lansia muda mencapai $67,32 \%$, lansia madya sebesar $26,30 \%$, dan lansia tua sebesar 6,38\%. Prevalensi lansia yang mengalami masalah dengan keseimbangan di Amerika Serikat terdapat sekitar 20\% hingga 30\% orang lanjut usia mengalami masalah dengan keseimbangan (Roberts et al., 2013). Dalam masyarakat umum, 1 dari 3 lansia berusia di atas 65 tahun dan 1 dari 2 lansia berusia di atas 80 tahun rata-rata mengalami jatuh setidaknya sekali setahun, dan 5\% mengalami jatuh dengan menyebabkan kerusakan yang serius (Bastani et al., 2017).

Keseimbangan adalah kemampuan untuk mempertahankan posisi tubuh ketika ditempatkan di berbagai posisi (Syah et al., 2017). Keseimbangan terbagi menjadi dua tipe umum yaitu keseimbangan statis dan keseimbangan dinamis. Keseimbangan statis adalah kemampuan untuk mempertahankan keseimbangan total tubuh ketika berdiri pada satu titik. Sedangkan keseimbangan dinamis yaitu keseimbangan yang dibutuhkan pada saat melakukan aktivitas atau selama melakukan gerakan (Sari, 2013). Keseimbangan dinamis sangatlah penting untuk keberlangsungan aktivitas sehari-hari pada setiap individu terlebih lansia. Ketika terjadi gangguan keseimbangan dinamis pada lansia, maka lansia akan memiliki masalah seperti berjalan, bergerak, berpindah tempat maupun lansia mengalami jatuh, sehingga lansia akan sulit melakukan aktivitas seperti normalnya.

Bentuk penanganan fisioterapi yang bisa diberikan untuk meningkatkan kesehatan pada lansia yang mengalami gangguan keseimbangan dinamis adalah dengan pemberian intervensi berupa core stability exercise dan tandem walking exercise. Core stability exercise merupakan kemampuan untuk mengendalikan posisi dan gerak dari trunk, pelvic dan kaki, yang memungkinkan terjadinya optimalisasi gerakan, transfer, dan kontrol kekuatan yang optimal. Core stability exercise ini mengacu pada latihan yang mengaktifkan pola motorik spesifik dengan stabilisasi tulang belakang dan kontrol postur tubuh pada trunk (Szafraniec et al., 2018). Sedangkan tandem walking exercise merupakan salah satu latihan yang bertujuan untuk melatih sikap atau posisi tubuh, koordinasi otot dan gerakan tubuh serta mengontrol keseimbangan dan melatih parameter yang terkait dengan keseimbangan individu yang merupakan kontrol mutlak atas ketetapan dari mobilitas tubuh (Valentin et al. 2013).

\section{Metode Penelitian}

Jenis penelitian yang dilakukan merupakan studi kasus (case study) dengan 1 orang responden yang merupakan pasien lansia dengan gangguan keseimbangan dinamis. Penelitian ini dilaksanakan Di Desa Paring Agung, Kecamatan Sungai Raya, Kabupaten Hulu Sungai Selatan, Provinsi 
Kalimantan Selatan selama 6 minggu dengan interval 3 kali seminggu dan dimulai pada minggu ke-2 bulan April sampai minggu ke-2 bulan Mei tahun 2020. Data penelitian yang diperoleh dalam melakukan penelitian ini didapat dari data primer yaitu data yang diperoleh dari pemeriksaan langsung kepada pasien.

Tahapan penatalaksanaan penelitian sebagai berikut:

1. Pada kunjungan awal, peneliti melakukan anamnesis dan pemeriksaan fisik kepada pasien seperti vital signs untuk mengetahui kondisi pasien saat hari tersebut, sekaligus menentukan pertimbangan untuk intensitas dan gerakan yang akan dilakukan.

2. Pada saat ini juga dilakukan pre test keseimbangan menggunakan Timed Up and Go Test (TUG) sebagai data awal. Pengukuran dimulai dengan responden duduk dikursi dengan ketinggian kursi sejajar dengan sudut lutut responden. Lalu terapis memberikan pengarahan kepada responden tentang apa yang akan responden lakukan nantinya. Terapis memberikan aba-aba kepada respon dengan mengucapkan kata 'mulai', kemudian terapis mulai merekam waktu percobaan dengan stopwatch yang dimulai ketika responden berdiri. Lalu responden berjalan ke arah kerucut sejauh 3 meter dan kemudian kembali lagi menuju kursi dan duduk kembali di kursi. Serta intruksikan kepada responden untuk berjalan secepat mungkin dan aman dengan mengikuti garis yang telah ditandai terapis. Setelah responden duduk kembali ke kursi semula, maka terapis matikan stopwatch dan lihat berapa waktu yang diperoleh (Hofheinz \& Mibs, 2016).

3. Setelah mendapatkan responden yang memiliki hasil TUG dengan interpretasi resiko jatuh, peneliti menjelaskan tujuan penelitian dan prosedur penelitian kepada calon responden. Bagi responden yang bersedia mengikuti penelitian, maka responden diminta untuk menandatangani surat persetujuan untuk menjadi responden (Informed consent) dan mengisi identitas responden penelitian.

4. Setelah pemeriksaan dilakukan dan telah dipastikan bahwa kondisi pasien aman untuk melakukan latihan maka peneliti memulai penatalaksanaan pemberian intervensi core stability exercise dan tandem walking exercise.

5. Setelah itu, penatalaksanaan core stability exercise dilakukan dalam 3 tahapan, yaitu pertama pemasanan yang memiliki 2 macam gerakan yaitu breathing exercise sebagai pengontrol napas sebelum dimulainya latihan dan cat-camel exercise. Masuk ke tahapan kedua yaitu gerakan inti, yang memiliki 3 gerakan dengan posisi supine lying dimana latihan inti ini terdapat latihan penguatan di dalamnya, gerakannya terdiri dari bridging exercise, cycling exercise, dan half sit-up exercise. Dan tahapan ketiga yaitu pendinginan, yang memiliki 1 gerakan dengan di dalamnya terdapat breathing exercise sebagai rileksasi. Kemudian diakhiri dengan gerakan tandem walking exercise yang dilakukan sebanyak 2-4 kali repetisi yang setiap sesi latihan tingkatan intensitas latihan selalu dinaikkan.

6. Peneliti datang ke rumah pasien $3 x$ seminggu selama 6 minggu berturut-turut dengan durasi penatalaksanaan 45 menit.

7. Sebelum penatalaksanaan selesai peneliti kembali melakukan pemeriksaan vital signs.

8. Setiap seminggu sekali setelah sesi latihan, peneliti selalu melakukan evaluasi nilai TUG responden.
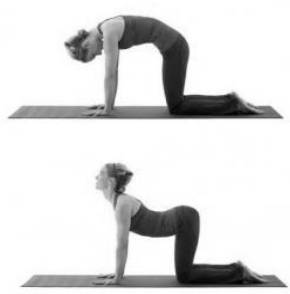

Gambar 1. Cat-camel exercise 
Fauziah, E., Zulfah, K. \& Oktaviani, Y. E. Fisiomu.2022 Vol 3(1): 16-22

DOI : $10.23917 /$ fisiomu.v3i1.14126

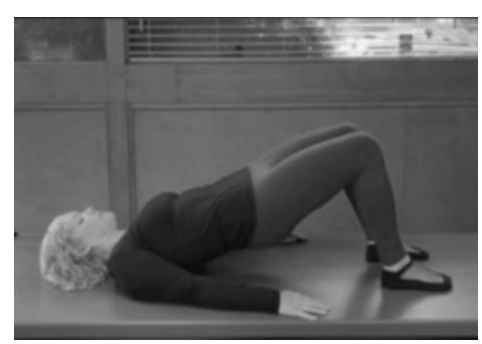

Gambar 2. Bridging exercise

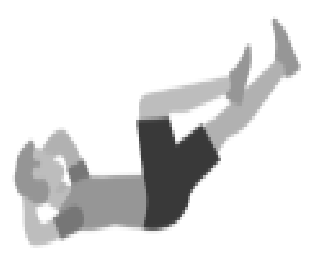

Gambar 3. Cycling exercise

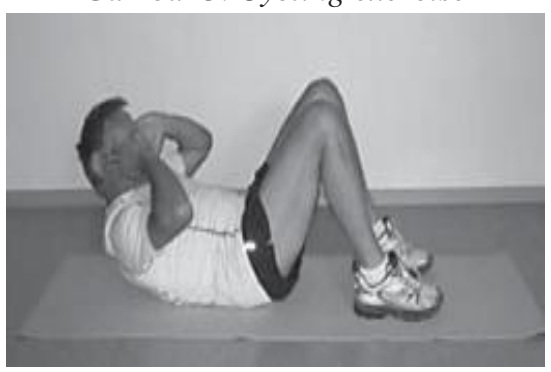

Gambar 4. Half sit-up exercise

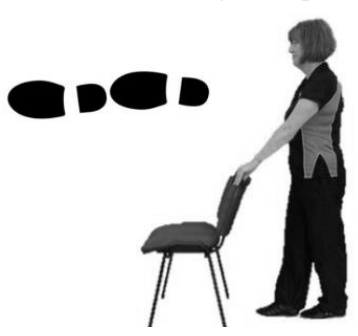

Gambar 5. Gerakan tandem walking exercise

\section{Hasil}

Berdasarkan pemeriksaan kepada pasien lansia yang mengalami gangguan keseimbangan dinamis, diperoleh hasil antara lain: karakteristik pasien adalah pasien laki-laki berusia 68 tahun dengan status pekerjaan petani. Pasien mengeluhkan bahwa pasien sering mengalami jatuh ketika berjalan dan kondisi tersebut sering pasien alami sejak 2 tahun belakangan ini dan terakhir jatuh 7 bulan lalu. Hasil uji TUG test ditemukan terdapatnya problematika berupa gangguan keseimbangan saat berjalan dan juga saat beraktivitas. Dari problematik yang didapatkan tersebut, peneliti memberikan penatalaksanaan untuk meningkatkan keseimbangan dinamis pasien menggunakan core stability exercise dan tandem walking exercise. Hasil keseimbangan pasien diukur dan dievaluasi setiap minggunya seperti yang tercantum dalam tabel berikut:

Tabel 1. Hasil Evaluasi nilai Timed Up and Go Test

\begin{tabular}{|c|c|c|c|}
\hline Minggu & $\begin{array}{l}\text { Tanggal } \\
\text { Evaluasi }\end{array}$ & Nilai & $\begin{array}{l}\text { Interpreta } \\
\text { si }\end{array}$ \\
\hline 1 & $\begin{array}{l}10 \text { April } \\
2020\end{array}$ & $20,82 \mathrm{~s}$ & $\begin{array}{l}\text { Resiko } \\
\text { jatuh } \\
\text { sedang }\end{array}$ \\
\hline 2 & $\begin{array}{l}17 \text { April } \\
2020\end{array}$ & $18,38 \mathrm{~s}$ & $\begin{array}{l}\text { Resiko } \\
\text { jatuh } \\
\text { ringan }\end{array}$ \\
\hline 3 & $\begin{array}{l}24 \text { April } \\
2020\end{array}$ & $16,28 \mathrm{~s}$ & $\begin{array}{l}\text { Resiko } \\
\text { jatuh } \\
\text { ringan }\end{array}$ \\
\hline 4 & $\begin{array}{l}01 \quad \text { Mei } \\
2020\end{array}$ & $16,43 \mathrm{~s}$ & $\begin{array}{l}\text { Resiko } \\
\text { jatuh } \\
\text { ringan }\end{array}$ \\
\hline 5 & $\begin{array}{l}08 \quad \text { Mei } \\
2020\end{array}$ & $14,33 \mathrm{~s}$ & $\begin{array}{l}\text { Resiko } \\
\text { jatuh } \\
\text { ringan }\end{array}$ \\
\hline 6 & $\begin{array}{l}15 \text { Mei } \\
2020\end{array}$ & $14,02 \mathrm{~s}$ & $\begin{array}{l}\text { Resiko } \\
\text { jatuh } \\
\text { ringan }\end{array}$ \\
\hline
\end{tabular}

Sumber : Data Primer

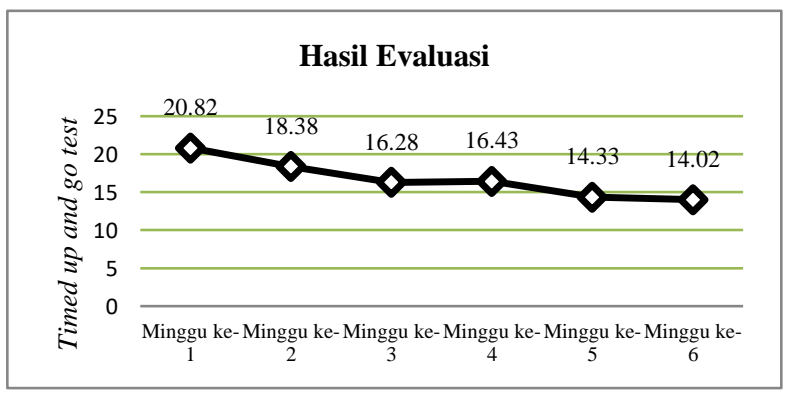

Gambar 6. Grafik hasil evaluasi keseimbangan dengan menggunakan TUG

\section{Pembahasan}

Dari penelitian yang telah dilakukan ditemukan bahwa pada pasien tersebut terjadi peningkatan keseimbangan ketika rutin melaksanakan latihan core stability exercise dan tandem walking exercise selama 6 minggu dengan 
interval 3 kali seminggu. Gangguan keseimbangan dinamis pada pasien lansia terjadi karena adanya permasalahan pada komponen-komponen pengontrol keseimbangan. Keseimbangan atau kontrol postural sangat tergantung pada interaksi antara input sensorik (somatosensorik, input visual dan input vestibular) dan respon motorik melalui sistem pengolahan integrasi pusat. Jika ada perubahan pada input sensorik hal itu akan menyebabkan perubahan dalam respon motorik (Ahmad et al., 2017).

Core stability exercise dapat memberikan efek dalam peningkatan keseimbangan dinamis. Hal ini dikarenakan core stability exercise akan meningkatkan fungsi neuromuskular (Magdalena, 2017). Terjadinya adaptasi neuromuskular disebabkan karena latihan ini dapat mempengaruhi efisiensi sistem neuromuskular dengan meningkatkan rekrut motor unit. Motor unit didefinisikan sebagai saraf motorik, dan semua serabut otot tersebut diinervasi oleh saraf motorik. Satu saraf motorik menginervasi lebih dari 100 serabut otot. Kekuatan kontraksi suatu otot secara langsung berkaitan dengan jumlah serabut otot yang terlibat. Semakin besar jumlah motor unit yang direkrut (semakin besar pula jumlah serabut otot yang direkrut) untuk melakukan pekerjaan sehingga semakin kuat kontraksi otot yang terlibat. Semakin banyak serabut otot yang diinervasi oleh saraf motorik, semakin besar pula power dan kekuatan otot yang dihasilkan (Higgin, 2011). Kekuatan otot tersebut akan membantu otot bekerja secara optimal untuk membentuk stabilitas yang baik sehingga tubuh dapat mempertahankan keseimbangannya pada saat melakukan berbagai gerakan (Dirmayanti, 2018).

Sedangkan tandem walking exercise sendiri merupakan suatu latihan proprioceptive melibatkan gerakan yang lambat pada setiap perpindahan gerak dan posisi agar nuclei subcortical dan basal ganglia dapat menganalisis sensasi posisi dan mengirimkan umpan balik berupa kontraksi otot yang diharapkan (Novianti, 2018). Terjadinya perubahan peningkatan keseimbangan dinamis saat diberikan intervensi tandem walking exercise juga disebabkan karena pada saat latihan, tubuh melakukan beberapa perubahan posisi. Informasi mengenai perubahan tersebut akan diterima oleh reseptor sensorik pada sistem vestibular yang bekerjasama dengan sistem visual dan somatosensoris. Sistem visual akan membantu menyampaikan informasi terkait posisi tubuh terhadap lingkungan disekitarnya berdasarkan sudut dan jarak dengan objek disekitarnya. Informasi yang diterima oleh sistem sensorik disampaikan ke sistem saraf pusat di otak, kemudian otak memberikan informasi agar sistem muskuloskeletal dapat bekerja secara sinergis untuk menghasilkan kesesuaian tubuh dan kontrol postural yang baik sehingga keseimbangan dapat dipertahankan (Mora \& Valencia, 2018).

\section{Kesimpulan dan Saran}

Hasil evaluasi dari penatalaksanaan fisioterapi yang dilakukan yaitu adanya peningkatan keseimbangan pada pasien lansia dengan gangguan keseimbangan dinamis dengan modalitas berupa core stability exercise dan tandem walking exercise yang diukur dengan timed up and go test (TUG) dengan nilai waktu TUG test sebelum terapi 20,82 detik dengan interpretasi resiko jatuh sedang dan setelah dilakukan terapi selama 6 minggu dengan interval 3 kali seminggu sehingga nilai TUG test menjad 14,02 detik dengan interpretasi resiko jatuh ringan. Saran untuk penelitian selanjutnya agar dapat menggunakan metode penelitian lain dengan menggunakan lebih banyak sampel penelitian.

\section{Ucapan Terimakasih}

Penulis menyampaikan ucapan terima kasih sedalam-dalamnya kepada semua pihak yang telah memberikan dukungan semangat, bantuan berupa bimbingan, arahan, motivasi, dan doa selama proses penelitian dan proses penulisan laporan penelitian. Penulis dengan penuh hormat dan tulus dari hati yang paling dalam menyampaikan rasa terimakasih sebesar-besarnya kepada rekan peneliti dan civitas akademika Politeknik Unggulan Kalimantan yang telah membantu dalam penelitian ini. 
DOI : $10.23917 /$ fisiomu.v3i1.14126

\section{Daftar Pustaka}

Ahmad, I., Hussain, E., Singla, D., Verma, S., \& Ali, K. Balance Training In Diabetic Peripheral Neuropathy: A Narrative Review. Jsm Diabetology And Management. 2017; 1(2). 1002.

Badan Pusat Statistik. Statistik Penduduk Lanjut Usia 2018. Subdirekto. Edited By Subdirektorat Statistik Pendidikan dan Kesejahteraan Sosial. 2018.

Bastani, M., Ghasemi, G., Sadeghi, M., Afshon, A., \& Sadeghi, H. The Effect of Selected Core Stability Exercises on Balance and Muscle Endurance in the Elderly Patients Undergoing Hemodialysis. Physical Treatments-Specific Physical Therapy Journal.2017; 7(2), 89-96.

Dirmayanti R.W. Pengaruh Elastic Band Exercise Terhadap Tingkat Keseimbangan Dinamis Dan Risiko Jatuh Pada Lanjut Usia Di Panti Sosial Tresna Werdha Gau Mabaji Gowa. Skripsi Diterbitkan. Makassar. Program Studi Fisioterapi Universitas Hasanuddin; 2018.

Higgins, M. Therapeutic Exercise: From Theory to Practice. Philadelphia: F.A. Davis Company. 2011.

Hofheinz, M., \& Mibs, M. The Prognostic Validity Of The Timed Up And Go Test With A Dual Task For Predicting The Risk Of Falls In The Elderly. Gerontology And Geriatric Medicine. 2016; 2, 2333721416637798. Pp. 1-5.

Magdalena, A.I. Pengaruh Core Stability Exercise terhadap Resiko Jatuh pada Lanjut Usia di Panti Sosial Tresna Werdha Gau Mabaji Gowa. Skripsi tidak diterbitkan. Makassar: Fakultas Kedokteran Universitas Hasanuddin; 2017.

Mora, J.C. dan Valencia, W.M. Exercise and Older Adult. Clinical Geriatric Medicine. 2018; 34(1).
Novianti., Jawi., Munawaroh, M., Griadhi. Latihan Jalan Tandem Lebih Meningkatkan Keseimbangan Tandem Stance Exercise Is More Increasing Balance Among The Elderly than Balance Strategy Exercise, Sport And Fitness Journal. 2018; 6(1), Pp. 117-122.

Sari, S. Peranan Gender dalam mempertahankan keseimbangan statis dan dinamis pada Mahasiswa STKIP PGRI Pontianak. Jurnal Pendidikan Olahraga. 2016; 2(2), 195-203.

Syah, I., Purnawati, S., \& Sugijanto. Efek Pelatihan Senam Lansia Dan Latihan Jalan Tandem Dalam Meningkatkan Keseimbangan Tubuh Lansia Di Panti Sosial Tresna Kasih Sayang Ibu Batusangkar Sumatra. Sport And Fitness Journal. 2017; 5(1), Pp. 8-16.

Shi, Z., \& Zhou, J. Family Medicine And Community Health Effect Of Core Stability Training On Balance In Elderly Women. Family Medicine And Community Health. 2014; 2(4), Pp. 48-52.

Szafraniec, R., Barańska, J., \& Kuczyński, M. Acute effects of core stability exercises on balance control. Acta of bioengineering and biomechanics. 2018; 20(3).

Valentin.L, Adiputra, Griadhi, Wiyana. Pemberian Latihan Jalan Tandem Lebih Baik Daripada Latihan One Legged Stance Untuk meningkatkan Keseimbangan Dinamis Pada Lansia Di Banjar Muncan Desa Kapal Kecamatan Mengwi Kabupaten Badung. 2018; 4(3), Pp. 36-40. United Nations. World Population Ageing 2017 Highlights (St/Esa/Ser.A/397). Department. Dancing Elderly Couple. Available. 2017. [update 2020 feb 10]. Available from: Http://Www.Un.Org/En/Development/De sa/Population/Publications/Pdf/Ageing/W pa2017_Highlights.Pdf. 